\title{
$\mathrm{CNC}$ 첨가에 따른 납축전지의 전기화학적 특성연구
}

\section{A Study on the Effects of CNC Addition on Electrochemical Properties of Lead-acid Battery}

\author{
김지 훈 ${ }^{1, a}$, 문준호 ${ }^{1}$, 문성용 ${ }^{1}$, 구본근 $^{2}$, 김기원 ${ }^{3}$ \\ (Jee Hoon Kim ${ }^{1, a}$, Jun Ho Mun', Seong Yong Moon', Bon Keun Ku², and Ki Won Kim³)
}

\begin{abstract}
CNC (Carbon Nano Colloid) was used as an additive to the positive electrode to improve the discharge performance of sealed lead-acid batteries. The cathode active material $\left(\mathrm{PbO}_{2}\right)$ has a relatively low utility of less than $60 \%$ compared with other kind of batteries, such as $\mathrm{Ni}-\mathrm{MH}$ and Lithium ion. In this study, to overcome the above-mentioned problem we investigated the effects of $\mathrm{CNC}$ addition on the enhancement of electrical connection with not-utilized $\mathrm{PbO}_{2}$ and resultantly electrical conductivity of electrode. We examined low rate discharge capacities, high rate discharge capacities and internal resistances of the batteries containing various amounts of CNC. From these results, we found out that the addition of $\mathrm{CNC}$ into the positive electrode made a significant improvement in high rate discharge capacity. We also suggested the optimum content of $\mathrm{CNC}$ material in positive electrode.
\end{abstract}

Key Words : CNC, Carbon nano colloid, Graphite, Lead acid battery

\section{1. 서 론}

휴대전자기기의 발달과 함께 전지 시장의 적용 영역이 급속한 확장 추세에 있으며, 현재 리튬이온 전지를 중심으로 한 2 차전지가 휴대전화, 노트북, 캠코더 및 전기자동차 등의 주 전원으로 각광 받 으며 사용되고 있다. 반면 납축전지는 자동차의 시 동용, 전동지게차 전원, 산업용 및 무정전 전원용 으로 사용하고 있으며 이를 대체할 전지를 개발하 고 있지 못하고 있다. 이것은 고출력, 대용량, 경제 성 맟 안전성 차원에서 납축전지를 능가하는 전지 를 찾지 못하고 있기 때문이다. 그러나 현재 전 세 계적인 원자재 값의 폭등으로 발생된 납 가격의 상승은 납수급의 어려움으로 이어져 납축전지 제

* 본 논문은 ATC과제 결과에 따른 투고논문임

1. 엔바로테크(주) 부설연구소

(울산시 울주군 웅촌면 고연리 974-1)

2. (주)엔비 기술연구소

3. 경상대학교 공과대학 나노 - 신소재공학부

a. Corresponding Author : jeehoon9@empal.com

접수일자 : 2008. 2. 4

심사완료 : 2008. 2. 24
조업체의 납축전지가격 인상 및 생산량 감소로 나 타나고 있다. 한편 납축전지 양극 활물질 이용율은 산업용 전지가 약 $35 \%$, 시동용 전지는 약 $60 \%$ 로 다른 2차 전지의 이용율에 비해 낮은 수준임을 알 수가 있다. 이에 본 연구에서는 액상나노탄소 (Carbon Nano Colloid, CNC) 제조기술을 바탕으로 납축전지의 저율방전특성, 고율방전특성 및 수명의 향상에 적합한 $\mathrm{CNC}$ 를 제조하여 전극의 전기전도 도 향상 및 활물질 이융율 증가를 통한 납축전지 용량향상 실험을 실시하였다. CNC 적용 전지는

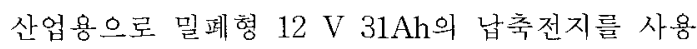
하였다. 제조된 전지의 분석 및 측정방법은 저율과 고율에 따른 전지의 방전전압, 방전용량 및 내부저 항으로 전지의 성능향상을 확인하였으며, 전극의 분석은 $\mathrm{SEM}, \mathrm{EDS}$ 및 $\mathrm{XRD}$ 를 통하여 극판의 표면 형상 및 성분을 확인하였다.

\section{2. 실 험}

\section{1 시약 및 재료}

납축전지의 양극 및 음극의 활물질은 $\mathrm{Pb}$ 를 ball 
mill type으로 제조하여 공기 중에서 분쇄한 연분 $(\alpha-\mathrm{PbO})$ 을 사용하였으며, 전극의 집전체로 사용되 는 그리드는 $\mathrm{Pb}-\mathrm{Ca}-\mathrm{Sn}-\mathrm{Al}$ 합금연을 사용하였다.

그림 1 은 $\mathrm{PbO}$ 의 표면형상을 $\mathrm{SEM}$ 으로 관찰한 사진으로 1차와 2차 입자로 나뉘어져 있고 사이즈 는 수백 $\mathrm{nm}$ 이며, 연분의 모양은 구형의 형상을 나 타내었다. 그림 2 는 $\mathrm{PbO}$ 의 원소성분을 $\mathrm{EDS}$ 를 이 용하여 분석한 결과로 $\mathrm{Pb}$ 와 $\mathrm{PbO}$ 가 공존하며 $\mathrm{PbO}$ 가 약 $70 \%$ 정도임을 알 수 있었다.

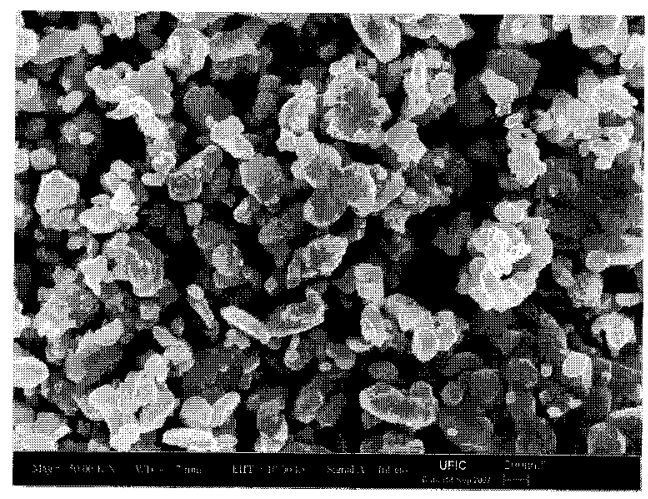

그림 1. $\mathrm{PbO}$ 의 표면형상관찰.

Fig. 1. SEM image of $\mathrm{a}-\mathrm{PbO}$.

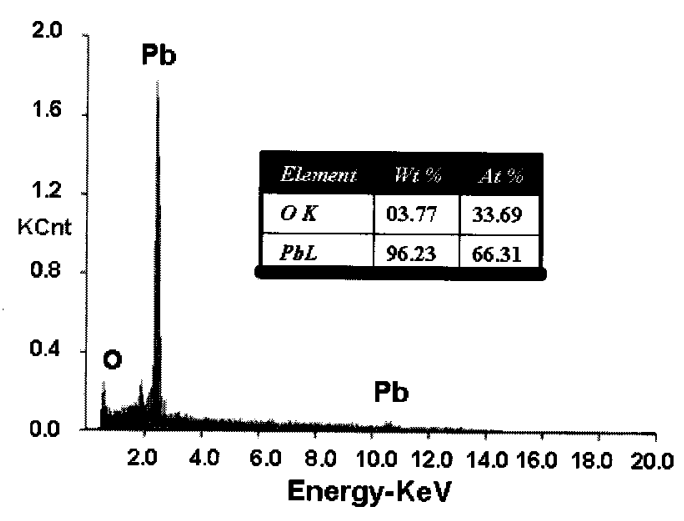

그림 2. 연분의 원소성분분석 결과.

Fig. 2. Element analyzed result of $\mathrm{PbO}$.

\section{$2.2 \mathrm{CNC}$ (Carbon nano colloid)의 물성}

납축전지 양극의 전도성 향상 및 활물질 이용율 증가를 위한 첨가제로 $\mathrm{CNC}$ 를 사용하였다. $\mathrm{CNC}$ 는 표면에 다수의 Carboxyl이 결합된 나노 입자의 흑
연(Graphite)이 물에 분산된 형태의 액상탄소나노 입자이다. 그림 3 은 $\mathrm{CNC}$ 의 입도분석결과로 약 2 0 200 nm의 입경을 가지고 있으며, 전체적인 물 성은 표 1 과 같다. 또한 $\mathrm{CNC}$ 는 분산안전성이 매 우 우수하여 첨가제 없이도 침전 되지 않으며 $\mathrm{PH}$ 2 3 정도의 콜로이드 수용액이다.

표 1. $\mathrm{CNC}$ 물성값.

Table 1. Properties of carbon nano colloid.

\begin{tabular}{|c|c|c|c|}
\hline Property & 측정기 기 & 목적 & 결과 \\
\hline Size & $\begin{array}{c}\text { Dynamic light } \\
\text { scattering } \\
\text { analysis }\end{array}$ & 입경분포 & $20 \sim 200 \mathrm{~nm}$ \\
\hline Shape & SEM, TEM & $\begin{array}{c}\text { 입자크기 } \\
\text { 형상 }\end{array}$ & $\begin{array}{c}10 \sim 20 \mathrm{~nm} \\
\text { 구형 }\end{array}$ \\
\hline $\begin{array}{c}\text { Chemical } \\
\text { Composition }\end{array}$ & FIIR & $\begin{array}{c}\text { 입자표면 } \\
\text { 작용기분석 }\end{array}$ & $\begin{array}{c}\text { 카르복실기 } \\
\text { 친수성작용기 }\end{array}$ \\
\hline analysis & 원소분석 & $\begin{array}{c}\mathrm{C}(54.03 \%) \\
\mathrm{H}(1.46 \%) \\
\mathrm{O}(43.09 \%)\end{array}$ \\
\hline PH & $\mathrm{PH}$ meter & 이온농도 & $2 \sim 3$ \\
\hline Put
\end{tabular}

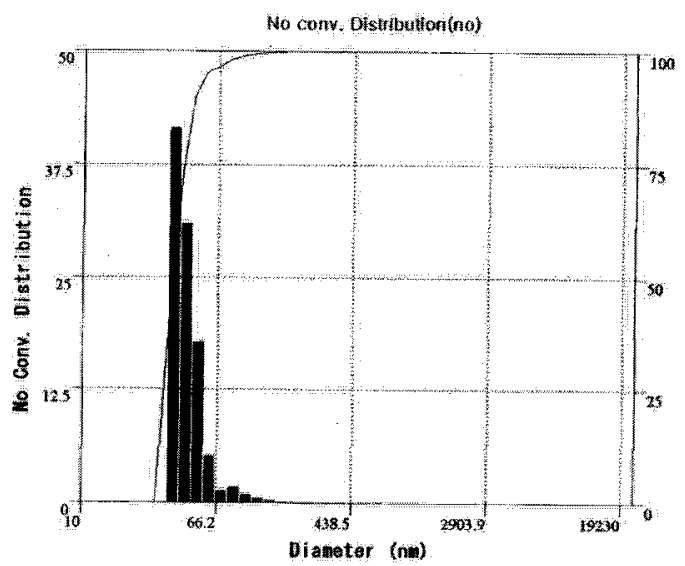

그림 3. $\mathrm{CNC}$ 의 입도분포.

Fig. 3. Particle size distribution of $\mathrm{CNC}$.

\section{$2.3 \mathrm{CNC}$ 제조방법}

$\mathrm{CNC}$ 는 흑연을 순수한 물에서 전기분해하여 제 조한다. 전기분해 결과 흑연은 표면이 산화되고 미 세하게 쪼개져 물에 용출되며, 생산과정에서 전기 
분해와[3] 동시에 단계별 초음파를 인가한다. 그 결과 표면에 Carboxyl이 발생하고 입자는 더욱 미 분화된다. 그림 4 는 흑연표면의 산화원리를 나타낸 그림으로 Macro Carbon을 순수한 물에서 전기화 학반응과 초음파 화학반응을 동시에 적용하여 '표 면에 다수의 Carboxyl이 결합된 Nano Carbon'을 생산하는 것이다. 초음파는 물리적으로 흑연입자를 잘게 나누기도 하지만 화학적으로 물분자 $\left(\mathrm{H}_{2} \mathrm{O}\right)$ 를 $\mathrm{H}+\mathrm{OH}$ Radical로 나누며 이것이 흑연표면을 화 학적으로 변화시킨다. 그 결과 황산이나 질산과 같 은 산화성 물질의 도움 없이 흑연 포면을 산화시 키고 Carboxyl을 형성한다.

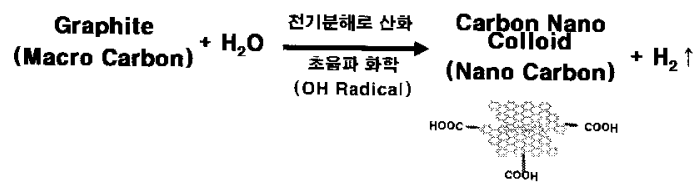

그림 4. 혹연표면의 산화원리.

Fig. 4. Mechanism of graphite oxidation.

\section{4 전극 및 전지제조}

밀폐형 납축전지의 양극 패이스트의 조성은 표 2 의 혼합비율로 연분 $(\mathrm{PbO})$, 화이버플럭(Binder), 증류수 $\left(\mathrm{H}_{2} \mathrm{O}\right), \mathrm{CNC}$ 첨가제, 황산 $\left(\mathrm{H}_{2} \mathrm{SO}_{4}\right)$ 을 최종밀도 가 $4.25\left(\mathrm{~g} / \mathrm{cm}^{3}\right)$ 가 될 때까지 약 1 시간 동안 혼합하 였다.

표 2. 양극 패이스트 조성.

Table 2. Content ratio of materials in cathode.

\begin{tabular}{|c|c|c|c|c|c|}
\hline Materials & $\begin{array}{c}\text { Lead } \\
\text { powder }\end{array}$ & $\mathrm{H}_{2} \mathrm{SO}_{4}$ & $\mathrm{H}_{2} \mathrm{O}$ & $\mathrm{CNC}$ & $\begin{array}{c}\text { 화이버 } \\
\text { 플럭 }\end{array}$ \\
\hline $\mathrm{wt} \%$ & $75 \sim 80$ & $10 \sim 12$ & $0 \sim 10.7$ & $0 \sim 0.4$ & 0.06 \\
\hline
\end{tabular}

혼합된 패이스트를 $\mathrm{Pb}-\mathrm{Ca}-\mathrm{Sn}$ Grid에 두께 $3.3 \pm 0.1(\mathrm{~mm})$, 무게 $510 \pm 10(\mathrm{~g})$ 으로 도장하여 $45{ }^{\circ} \mathrm{C}$ 에 서 40시간 숙성한 후 $120{ }^{\circ} \mathrm{C}$ 에서 3 -4시간 건조하 여 숙성, 건조극판을 완성하였다. 극판제조시 첨가 된 $\mathrm{CNC}$ 함량을 $0,0.1,0.2,0.3,0.4 \mathrm{wt} \%$ 로 변화시 켜 5 종류의 극판을 제조하였다.

음극 패이스트의 조성은 표 3 의 혼합비율로 연 분 $(\mathrm{PbO})$, 화이버폴럭(Binder), 증류수 $\left(\mathrm{H}_{2} \mathrm{O}\right), \mathrm{CNC}$ 첨 가제, 황산 $\left(\mathrm{H}_{2} \mathrm{SO}_{4}\right)$ 을 최종밀도가 $4.4\left(\mathrm{~g} / \mathrm{cm}^{3}\right)$ 가 될 때 까지 약 30 분 동안 혼합하였다. 혼합된 패이스트를 $\mathrm{Pb}-\mathrm{Ca}-\mathrm{Sn}$ Grid에 두께 $2.3 \pm 0.1(\mathrm{~mm})$, 무게 $357 \pm 7(\mathrm{~g})$
으로 도장하여 양극극판과 같은 조건으로 숙성한 후 $125{ }^{\circ} \mathrm{C}$ 에서 3.3 시간 건조하여 숙성, 건조극판을 완성하였다.

\section{표 3. 음극 패이스트 조성.}

Table 3. Content ratio of materials in anode.

\begin{tabular}{|c|c|c|c|c|c|}
\hline Materials & $\begin{array}{c}\text { Lead } \\
\text { powder }\end{array}$ & $\mathrm{H}_{2} \mathrm{SO}_{4}$ & $\mathrm{H}_{2} \mathrm{O}$ & $\begin{array}{c}\text { 화이버 } \\
\text { 플럭 }\end{array}$ & 기 타 \\
\hline wt\% & $75 \sim 80$ & $10 \sim 12$ & $9 \sim 10$ & 0.04 & 1.7 \\
\hline
\end{tabular}

숙성, 건조가 완료된 양극과 음극극판을 비중 $1.05 \pm 0.01 \mathrm{~S} . G$ 황산용액이 담긴 화성조에서 $20 \mathrm{~h}$ 율 로 $500 \%$ 의 전기량을 인가하여 화성극판을 제조 하였다. 화성 후 극판을 수세, 건조하여 최종 극판 을 완성하였으며 그림 5의 (a)는 숙성 후 양극극 판, (b)는 화성, 건조 후의 양극극판 사진으로 그림 과 같이 중간부분의 시료를 채취하여 $\mathrm{XRD}$ 로 성분 을 분석하였다. [a]

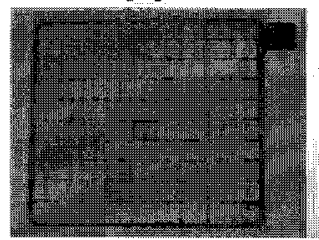

[b]

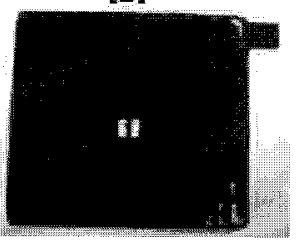

그림 5. 숙성과 화성 후 양극 극판의 형상.

Fig. 5. Image of positive electrode of after curing and formation.

화성 후 양극극판 18매, 음극극판 24매를 AGM 격리막으로 적층, 극군용접, 전조차입, 셀용접, 카 바접착,단자용접 및 액주입의 순서로 그림 6 과 같 은 공정으로 전지를 조립한 후 전해액은 1.320 S.G 비중의 황산을 $270 \mathrm{cc}$ 자동주입기를 이용하어 주 입하였다[5].

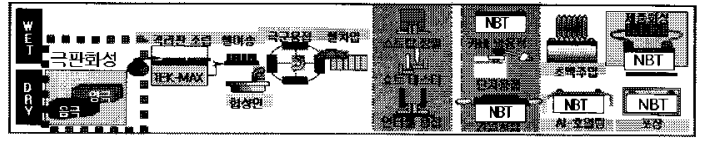

그림 6. 화성 후 전지조립 공정도.

Fig. 6. Assembly process of Lead acid battery. 


\section{3. $\mathrm{CNC}$ 함량에 따른 시험결과 및 고찰}

$3.1 \mathrm{CNC}$ 첨가에 따른 납축전지 성능향상의 이 론적 배경

납축전지의 양극은 방전이 진행되면 전기전도성 이 없는 황산납이 증가하여 집전능력이 현저하게 낮아진다. 그래서 통상적으로 산업용 납축전지는 양극 활물질의 약 $35 \%$ 밖에 충-방전에 사용하 지 못한다. $\mathrm{CNC}$ 는 탄소이므로 방전이 진행되어도 그림 7과 같이 전기전도체로 남아 집전능력의 저 하를 줄여주는 역할을 한다. 또한 $\mathrm{CNC}$ 는 나노크 기의 탄소입자이므로 양극극판에 고르게 분산되어 방전시 반응에 참여하지 못하는 $\mathrm{PbO}_{2}$ 의 이용율을 향상시킨다 $[1,2]$.

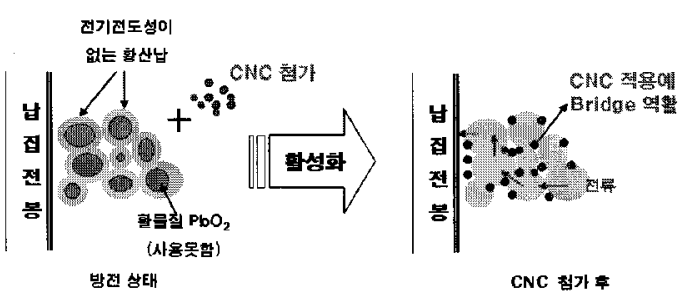

그림 7. 납축전지의 $\mathrm{CNC}$ 작용원리.

Fig. 7. Mechanism for applying $\mathrm{CNC}$ to lead acid battery.

\section{2 숙성 및 화성극판의 성분 분석 결과}

극판내의 $\mathrm{CNC}$ 함량에 따라 그림 5 와 같이 밀폐 형 납축전지 숙성 및 화성극판의 시료를 채춰하여 $\mathrm{XRD}$ 로 성분을 분석하였다. 그 결과 그림 8과 같 이 숙성된 극판은 다량의 $\alpha-\mathrm{PbO}, 3 \mathrm{BS}$ 그리고 소 량의 $\alpha-\mathrm{PbO}_{2}, \mathrm{~Pb}_{3} \mathrm{O}_{4}$ 맟 $4 \mathrm{BS}$ 가 관찰되었다. 또한 $\mathrm{CNC}$ 함량이 증가할수록 $3 \mathrm{BS}, 4 \mathrm{BS}$ 의 main peak인 $27.5^{\circ}$ 부근의 회절강도가 $\mathrm{a}-\mathrm{PbO} 32^{\circ}$ 의 회절강도 보다 커지는 것으로 보아 $\mathrm{CNC}$ 함량이 증가할수록 $3 \mathrm{BS}$ 가 많이 형성되는 것을 볼 수 있었다. 일반적 으로 $3 \mathrm{BS}$ 의 회절 peak는 $4 \mathrm{BS}$ 와 거의 일치하여 구 분하기 어려우나 그림 9의 화성된 극판의 결과에 서 $\beta-\mathrm{PbO}_{2}$ 가 다량 존재하는 것으로 보아 숙성 후 $3 \mathrm{BS}$ 가 주로 형성된 것으로 판단 할 수 있었다[4]. 숙성 후 $3 \mathrm{BS}$ 가 다량 형성되고 화성 시 $\beta-\mathrm{PbO}_{2}$ 가 주로형성이 되는 것으로 보아 초기옹량이 우수한 전지가 제조될 것으로 판단되었다.

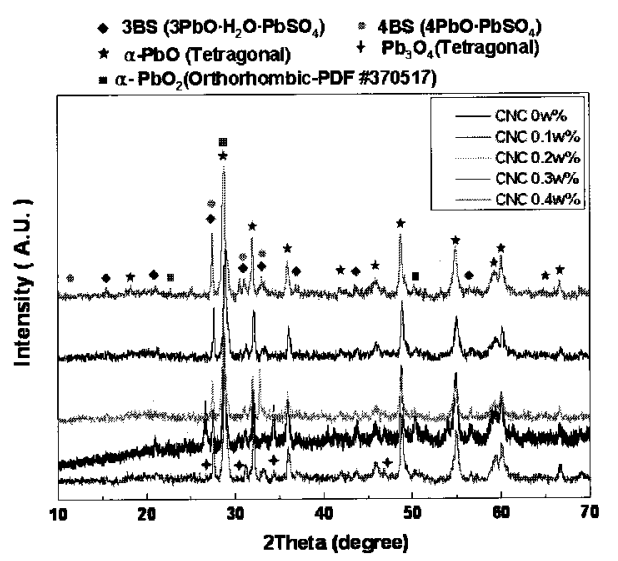

그림 8. $\mathrm{CNC}$ 함량에 따른 숙성극판의 $\mathrm{XRD}$ 분석 결과.

Fig. 8. X-ray diffraction patterns of curing electrode of according to amount $\mathrm{CNC}$ in electrode.

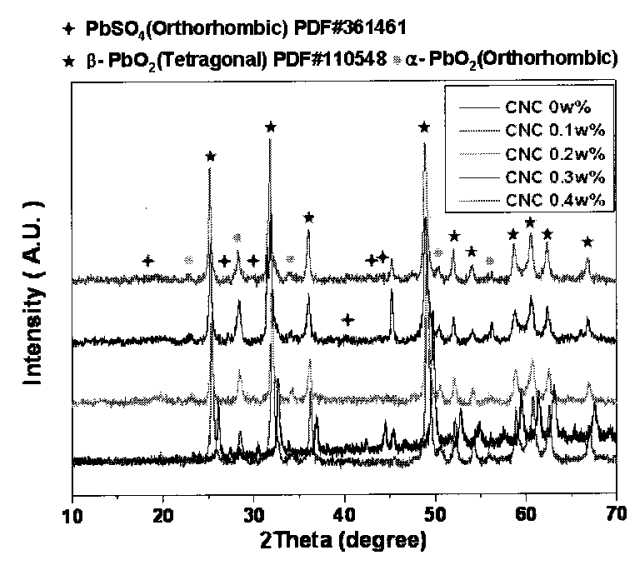

그림 9. $\mathrm{CNC}$ 함량에 따른 화성극판의 $\mathrm{XRD}$ 분석 결과.

Fig. 9. X-ray diffraction patterns of formation electrode of according to amount CNC in electrode.

\section{3 숙성 및 화성극판의 표면형상 관찰결과}

극판의 표면형상관찰은 극판의 표면을 제거한 후 $\mathrm{SEM}$ 을 통해 $10 \mathrm{~K}$ 의 배율로 관찰하였다. 그 결 과 숙성극판은 그림 10 과 같이 $3 \mu \mathrm{m}$ 이하의 침상모 양 결정형상을 나타내는 $3 \mathrm{BS}$ 가 관찰되었으며, $\mathrm{CNC}$ 함량이 증가할수록 $3 \mathrm{BS}$ 의 형상이 뚜렷이 나 타났다. 

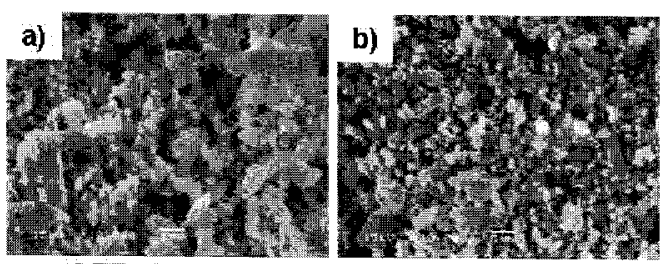

\section{c)}

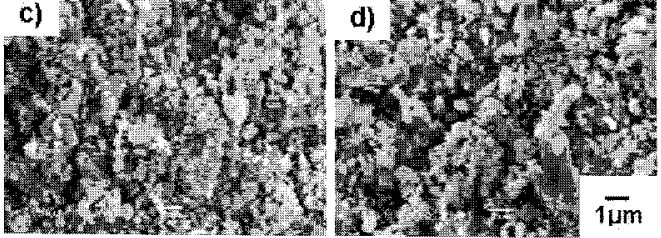

그림 10. $\mathrm{CNC}$ 함량에 따른 숙성극판의 표면형상관찰.

Fig. 10. SEM image of curing electrode of according to amount $\mathrm{CNC}$ in electrode : (a) $\mathrm{CNC} 0.1 \mathrm{wt} \%$, (b) $\mathrm{CNC} 0.2 \mathrm{wt} \%$, (c) $\mathrm{CNC} 0.3 \mathrm{wt} \%$, (d) $\mathrm{CNC} 0.4 \mathrm{wt} \%$.
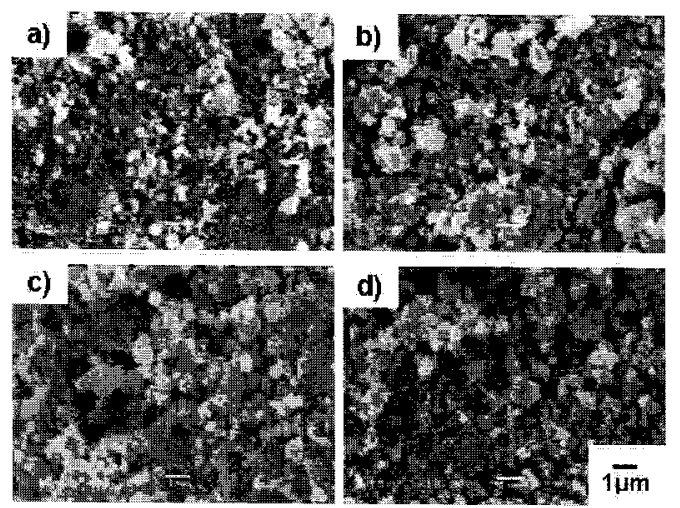

그림 11. $\mathrm{CNC}$ 함량에 따른 화성극판의 표면형상 관찰.

Fig. 11. SEM image of fomation electrode of according to amount $\mathrm{CNC}$ in electrode :(a) $\mathrm{CNC} 0.1 \mathrm{wt} \%$, (b) $\mathrm{CNC} 0.2 \mathrm{wt} \%$, (c) $\mathrm{CNC} 0.3 \mathrm{wt} \%$, (d) $\mathrm{CNC} 0.4 \mathrm{wt} \%$.

화성극판은 그림 11 과 같이 모든 종류의 극판에 서 약 $1 \mu \mathrm{m}$ 의 크기를 가지는 구형의 $\mathrm{PbO}_{2}$ 가 형성 되었다[4]. 또한 그림 12 와 같이 $\mathrm{CNC}$ 가 첨가된 화 성극판을 SEM으로 관찰 후 $\mathrm{EDS}$ 를 이용하여 극깐 내 carbon의 분산정도를 관찰하였다. 그림 12 의 (a)는 저배율 ( 300 배)에서 carbon의 분산정도를 관 찰한 결과로 극판내에 carbon이 균일하게 분포되 어 있는 것을 볼 수가 있었으며, 중간부분의 어두운

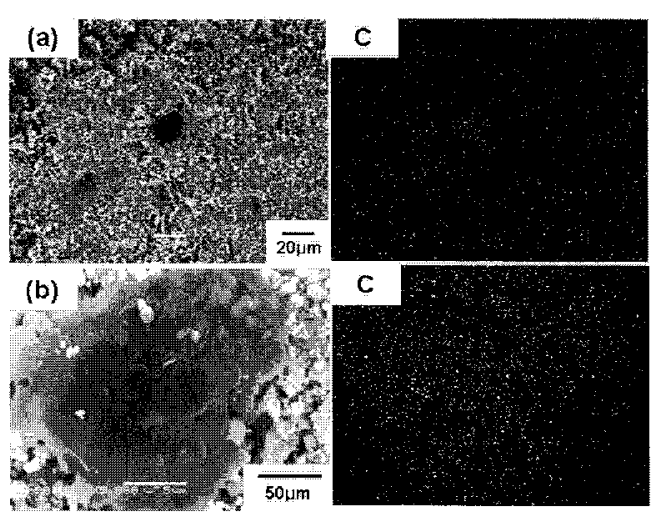

그림 12. $\mathrm{CNC}$ 가 첨가된 화성극판의 $\mathrm{EDS}$ 에 의한 Carbon 분포.

Fig. 12. EDS mapping image of fomation electrode of $\mathrm{CNC}$ additive

점을 고배율로 관찰해본 결과가 (b)이며 주위보다 carbon의 함량이 더욱 많은 것을 알 수가 있었다. 일반적으로 납축전지의 극판은 화성 후 생성되는 물질 중에서 크기가 큰 물질은 $\mathrm{PbSO}_{4}$ 로 고배율 (5000배) (b)를 보면 carbon이 화성 시에 생성되는 $\mathrm{PbSO}_{4}$ 주위에 집중적으로 분포되어 있는 것으로 판단된다.

만일 $\mathrm{CNC}$ 가 충전 중 $\mathrm{PbO}_{2}$ 로 환원되지 못하는 $\mathrm{PbSO}_{4}$ 와 $\mathrm{PbO}_{2}$ 사이에 중간자로 참여하여 전자통 로를 제공하거나, 상대적으로 전기전도도가 낮고 크기가 큰 $\mathrm{PbSO}_{4}$ 가 전지의 활물질인 $\mathrm{PbO}_{2}$ 의 화학 반응저해를 막는 활물질 반응 촉매역할로 작용한 다면 충전 시 충전 - 수입성을 향상시킬 수 있을 것으로 사료된다.

\section{4 전지의 저율방전 성능비교}

전지의 저율방전성능 평가방법으로 $20 \mathrm{~h} \mathrm{rate}$ 로 종지전압을 $10.5 \mathrm{~V}$ 로 하여 방전하였다. 방전한 결 과 $\mathrm{CNC}$ 가 첨가되지 않은 전지에 비해 용량의 변화 가 최고 $5 \%$ 향상된 것으로 나타났다. 그림 13 의 $\mathrm{CNC}$ 첨가함량에 따른 전지의 방전결과를 본다면 $\mathrm{CNC}$ 의 첨가함량이 증가할수록 용량이 향상되고 있으며, $0.3 \mathrm{wt} \%$ 에서 최고값을 나타내었다.

\section{5 전지의 $1 \mathrm{C}$ rate 고율방전 성능비교}

그림 14와 같이 $\mathrm{CNC}$ 함량변화에 따라 $1 \mathrm{C}$ rate 에서 방전한 결과 $\mathrm{CNC}$ 가 첨가되지 않은 전지에 비해 $\mathrm{CNC}$ 첨가함량이 $0.3 \mathrm{wt} \%$ 에서 $8.8 \%$ 의 옹량 


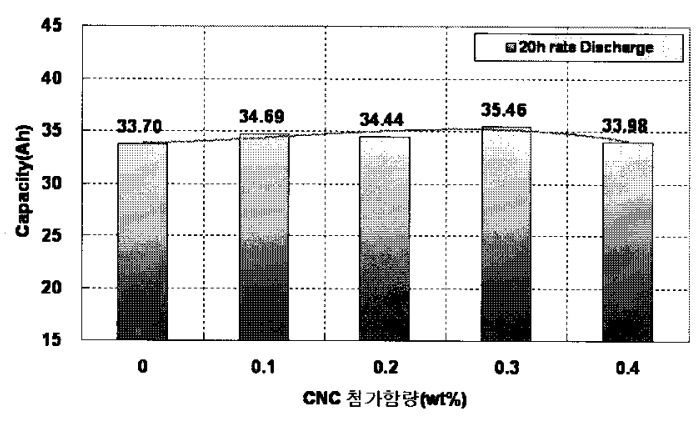

그림 13. $\mathrm{CNC}$ 함량에 따른 $20 \mathrm{~h}$ 율 방전용량.

Fig. 13. Variation of $20 \mathrm{~h}$ rate discharge capacity according to amount $\mathrm{CNC}$ in electrode [20h rate current : $1.55 \mathrm{~A}$ ].

향상을 보였다. $20 \mathrm{~h}$ rate 저율방전에서는 $\mathrm{CNC}$ 첨 가의 효과가 $5 \%$ 였지만 $1 \mathrm{C}$ rate의 고율방전에서 더 높은 용량향상을 보이는 것은 현재 첨가되고 있는 $\mathrm{CNC}$ 의 효과는 극판내부에서 방전 시 도전효 과가 뛰어나다고 판단할 수 있으며, 방전 중 $\mathrm{PbSO}_{4}$ 에 둘러싸인 $\mathrm{PbO}_{2}$ 의 반응을 원활하게 하는 역할에 의해 고율방전성능이 향상된 것으로 판단 된다.

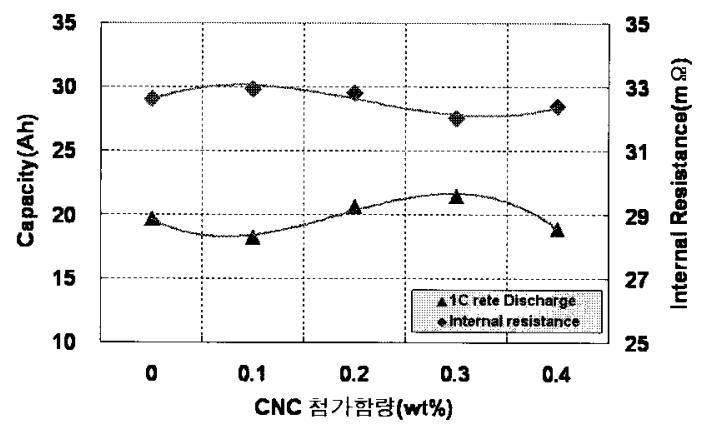

그림 14. $\mathrm{CNC}$ 함량에 따른 $1 \mathrm{C}$ 율 방전용량 및 내 부저항.

Fig. 14. Variation of $\mathrm{CC}$ rate discharge capacity and internal resistance according to amount $\mathrm{CNC}$ in electrode $[1 \mathrm{C}$ rate current : $31 \mathrm{~A}]$.

또한 그림 14 의 전지내부저항은 $\mathrm{DC}$ 로 측정한 내부저항 값으로 $1 \mathrm{C}$ rate의 방전용량 값과 상대적 인 경향을 보이고 있으며, $\mathrm{CNC}$ 첨가가 $0.3 \mathrm{wt} \%$ 에 서 가장 작은 내부저항 값을 나타내었다.

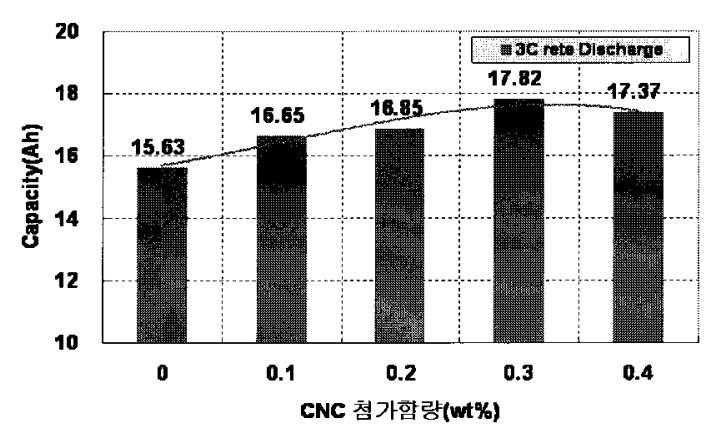

그림 15. $\mathrm{CNC}$ 함량에 따른 $3 \mathrm{C}$ 율 방전용량 그래프.

Fig. 15. Variation of $3 \mathrm{C}$ rate discharge capacity according to amount $\mathrm{CNC}$ in electrode [3C rate current : $93 \mathrm{~A}$ ].

\section{6 전지의 $3 \mathrm{C}$ rate 고율방전 성능비교}

그림 15 의 $3 \mathrm{C}$ rate방전에서는 기준전지보다 전 체적으로 $\mathrm{CNC}$ 의 함량이 증가할수록 방전용량이 향상 되었으며, $\mathrm{CNC}$ 첨가함량이 $0.3 \mathrm{wt} \%$ 에서 기 준전지의 방전용량보다 $14.0 \%$ 의 높은 증가를 보 였다. 그러나 $\mathrm{CNC}$ 첨가함량이 $0.4 \mathrm{wt} \%$ 에서는 오 히려 방전용량이 감소하는 경향을 보였다. 이것은 $\mathrm{CNC}$ 첨가로 인한 전기전도도의 향상보다는 오히려 방전 시 전지내부의 화학적 반응을 $\mathrm{CNC}$ 가 방해하 는 요인으로 작용했기 때문인 것으로 퐌단된다.

또한 그림 16 은 $\mathrm{AC}$ 내부저항 측정기로 전지의 내부저항을 측정한 결과 값으로 그림 13 의 $\mathrm{DC}$ 저 항측정값의 경향과 같이 $\mathrm{CNC}$ 첨가시 $0.3 \mathrm{wt} \%$ 에 서 가장 작은 내부저항 값을 나타내었다. 위의 내 용을 종합해 볼 때 $20 \mathrm{~h}$ rate 방전에서는 $\mathrm{CNC}$ 첨 가의 효과가 $5 \%$ 이내였지만, $1 \mathrm{C}$ 및 $3 \mathrm{C}$ rate의 고 율방전 용량향상으로 보아 현재 첨가되고 있는 $\mathrm{CNC}$ 의 첨가효과는 저율방전 보다 고율방전에서 효과가 뛰어나다고 할 수 있다.

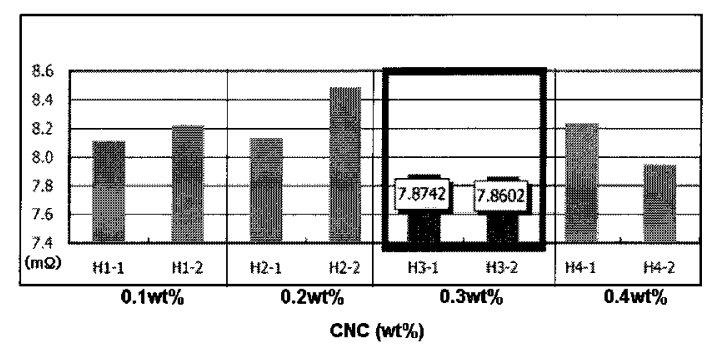

그림 16. $\mathrm{CNC}$ 함랑에 따른 내부저항.

Fig. 16. Variation of internal resistance according to amount $\mathrm{CNC}$ in electrode. 


\section{4. 결 론}

$\mathrm{CNC}$ 함량에 따른 저율과 고율방전 시험 및 화성 극판의 성분을 비교 분석해본 결과 $20 \mathrm{~h}$ rate의 저 율방전 보다 $1 \mathrm{C}$ 및 $3 \mathrm{C}$ rate 고율방전특성에서 용 량 향상을 나타내었다. 특혀 $3 \mathrm{C}$ rate방전 중 $\mathrm{CNC}$ 의 함량이 $0.3 \mathrm{wt} \%$ 에서 $\mathrm{CNC}$ 가 미 첨가된 전지에 비해 최고 $14.0 \%$ 의 용량향상을 보였다. 따라서 현재 납축전지의 양극극판에 첨가되는 $\mathrm{CNC}$ 의 최 적함량은 $0.3 \mathrm{wt} \%$ 로 나타났다. 본 연구에서 납축 전지에 $\mathrm{CNC}$ 첨가효과는 저율에서는 미흡하지만 고율방전에서 우수한 특성을 보였다. 그 이유는 $\mathrm{CNC}$ 가 전지의 방전 시 양극극판의 전기전도성을 향상시키는 것으로 판단되어지며, 양극극판의 전기 전도성이 향상되는 원인은 다음과 같다. 일반적으 로 전지의 방전반응 중에 생성되는 $\mathrm{PbSO}_{4}$ 는 극판 의 표면에서부터 생성되어 전지의 활물질로 사용 되는 $\mathrm{PbO}_{2}$ 의 반응을 저해시킨다. 따라서 현재 납 축전지의 첨가제로 개발된 나노 사이즈의 $\mathrm{CNC}$ 가 $\mathrm{PbSO}_{4}$ 로 둘러싸인 $\mathrm{PbO}_{2}$ 의 사이에서 $\mathrm{PbO}_{2}$ 의 반응 을 증가시키는 중간자의 역할을 하여 활물질의 이 용율을 향상시킨다. 방전 시 극판의 표면에 집중적 으로 $\mathrm{PbSO}_{4}$ 가 생성되는 고율방전에서 더욱 그 효 과가 증가되는 것으로 판단되어 진다.

또한 $\mathrm{CNC}$ 첨가효과가 전기전도도의 향상 외 $\mathrm{PbSO}_{4}$ 와 $\mathrm{CNC}$ 의 화학적 결합 및 $\mathrm{PbSO}_{4}$ 가 $\mathrm{CNC}$ 내
부로의 인터칼레이션 반응여부 관계를 알아보기 위해 수명시험과 충·방전이 진행된 전지의 극판 분석을 통해 향후 연구가 진행될 예정이다.

\section{참고 문헌}

[1] A. Tokunaga, M. Tsubota, K. Yonezu, and K. Ando, "Effect of anisotropic graphite on discharge performance of positive plates in pasted-type lead-acide batteries", J. Electrochem. Soc., Vol. 134, No. 3, p, 525, 1987.

[2] A. Tokunaga, M. Tsubota, and K. Yonezu, "Appication of anisotropic graphite to sealed lead-acide batteries", J. Electrochem. Soc., Vol. 136, No. 1, p. 33, 1989.

[3] T. Kimura, A. Ishiguro, Y. Andou, and K. Fujita, "Effect of electrochemically oxidized carbon colloid on lead acid batteries", Journal of power Sources, Vol. 85, p. 149, 2000.

[4] 김상필, 남기윤, "숙성조건에 따른 연축전지용 양극 극판의 특성연구", 한국전기전자재료학회 1995춘계학술대회논문집, p. 177, 1995.

[5] G. Toussaint, L. Torcheux, J. Alzieu, and J. C. Camps, "Effect of additives in compressed lead acid batteries", Journal of power Sources, Vol. 144, p. 546, 2005. 